\title{
SOCIALIZAÇÃO NO ESPAÇO SAGRADO EM PRESIDENTE PRUDENTE-SP
}

Andressa Almeida Silva, Fabrícia Dias da Cunha de Moraes Fernandes Borges.

Universidade do Oeste Paulista, UNOESTE, Faculdade de Engenharias e Arquitetura e Urbanismo, Presidente Prudente, SP. E-mail: andressa.almeida.s@hotmail.com.

\section{RESUMO}

O presente trabalho consiste em analisar a relevância social e religiosa de um espaço sagrado e seu processo evolutivo entendendo a relação dos ambientes sacros com o homem onde na atualidade o papel da igreja católica se volta para propósitos mais sociais, analisando assim a importância da socialização religiosa presente nesse local. A dissertação aponta ainda, a significância da paróquia Nossa Senhora do Carmo - Vila Maristela na cidade de Presidente Prudente para a região, destacando a história, desenvolvimento, e espaços da paróquia contribuindo juntamente com a memória e identidade não apenas aos participantes como também a toda população da cidade e região.

Palavras-chave: Espaço Sagrado, Socialização, Presidente Prudente, Paróquia, Identidade.

\section{SOCIALIZATION IN THE SACRED SPACE IN PRESIDENTE PRUDENTE-SP}

\begin{abstract}
The present work consists in analysing the relevance of social and religious a sacred space and its evolutionary process in the understanding of the relationship of the environments of worship with the man where in actuality the role of the catholic church in the back for the purpose more social, by analyzing the importance of socialization religious present at this location. The dissertation also points out, the significance of the parish Our Lady of the Carmo - Vila Maristela in the city of President Prudent for the region, highlighting the history, development, and spaces of the parish by contributing, along with the memory and identity not only to the participants but also the entire population of the town and the region.
\end{abstract}

Keywords: Sacred Space, Socialization, Presidente Prudente, Parish, Identity 


\section{INTRODUÇÃO}

O estudo atribui a importância contínua do homem de se relacionar com o divino e com o próximo, visto que a construção de espaço religioso parte do próprio ser humano em se rodear do sagrado. Assim para Fabien (2015) o indivíduo tende a buscar uma socialização, normalmente iniciada nas principais bases: família, escola, igreja, etc. Ou seja, os espaços sagrados atuam na manifestação de sentimentos próprios adquirindo um simbolismo heterogêneo aos demais lugares. Sabendo da importância da Religião desde o início da humanidade, como um meio de formação de valores para as pessoas, podendo através deste formar opiniões de convívio social.

A partir do Concílio Vaticano II, o conceito de igreja se torna mais amplo, proporcionando alterações no catolicismo capaz de atender as demandas da sociedade moderna. Assim, para Franco (2011) a igreja se torna mais humanitária, passando a ser um lugar não somente de celebrações, mas de encontros, proporcionando a socialização da comunidade através de lugares para serviços prestados em função do próximo.

Com base nisso foram analisadas a história e dependências da paróquia Nossa Senhora do Carmo, Localizada na cidade de Presidente Prudente, estudando sua importância histórica e revelando o valor material e imaterial do local.

\section{METODOLOGIA}

A metodologia empregada foi baseada em levantamentos bibliográficos, consultando livros, artigos, e material disponibilizado na internet, buscando conceitos científicos. Pesquisas in loco foram feitas para descriminar seu levantamento arquitetônico atual, através de medidas, fotografias, e tendo a vivencia local podendo colher um pouco da sua rotina.

\section{DISCUSSÃO}

Desde a antiguidade, nos primórdios das civilizações em que se tem relato, o homem busca uma proximidade com os símbolos, afim de materializar um sentimento próprio. Para Oliveira (2010) o simbolismo é uma forma do homem expressar aquilo que é invisível aos olhos, tornando uma forma abstrata, em real. "O homem necessita dar ao imperceptível uma forma perceptível, por isso a simbolização se produz em um contexto misterioso, já que o objeto simbolizado tem algo de inapreensível". (OLIVEIRA, Apud SEBASTIAN, 1996, p.17).

A necessidade em reproduzir um universo simbólico, traduz o desejo do homem em recorrer a algo efetivo diante das suas próprias angustias e emoções. A análise de Oliveira (2010) trata a religião como uma área composta de linguagem simbólica, representando uma definição em caráter religioso para os sentimentos humanos. Como por exemplo, ao representar uma divindade capaz de ouvir e atender as condições da vida humana de forma artística, seja em uma pintura ou um espaço edificado ou até mesmo na natureza, é um encontro simbólico do homem com o sagrado.

Se tratando de espaço sagrados católicos, em suas análises Franco (2011) explica que com o passar dos anos a definição de igreja molda-se as necessidades e vivencia da época. Com isso, confere-se que a igreja católica contemporânea adquire princípios mais humanos, a partir de vínculos sociais. Assim, o Papa João VI em 1962 solicita um concílio ecumênico que reuniria os bispos para discutir as questões relacionadas a igreja católica, denominado Concílio Vaticano II. Dentre os efeitos das decisões, posteriormente, a forma de celebração nos templos religioso passa por mudanças, com o princípio de participação da comunidade. (VALBUZA, 2015)

Segundo Frade (2007) a integração dos fiéis nas atividades da igreja, conduziu os participantes a terem a percepção de viver a religião e de estarem reunidos para um só Deus. Com isso, a arquitetura contemporânea passa a privilegiar espaços para a comunidade, dedicando-se a socialização. Para os cristãos a igreja em si, não se define pelo templo religioso, ou elementos 
místicos que a compõe, mas é representada pelos próprios membro pertencentes a comunidade. Para Franco (2011) o catolicismo atual acredita na mística religiosa que as pessoas reunidas trazem, assim o lugar considerado sagrado é o espaço de realizações e socialização dos fiéis.

Com isso, no aspecto religioso, ao analisar os estudos de Fabien (2015) com Franco (2011) as contribuições na socialização acontecem muitas vezes no lugar de convivência cristã, ou seja, o espaço sagrado deve ser considerado não apenas como um lugar de celebrações e devoção, mas de relação social. Com isso, a socialização não é uma oposição a presença constante de uma crença em um fenômeno religioso, mas a elevação conceitual de um planejamento de um espaço sacro monumental capaz de promover encontros.

Posto isto, a paróquia Nossa Senhora do Carmo na cidade de Presidente Prudente traz consigo, não apenas uma importância individual por pessoas que frequentam o local como para a cidade e região. A história da paróquia se inicia na década de $40 \mathrm{com}$ o início do loteamento do bairro Vila Maristela. O parcelamento do solo, a comando de Antônio Lopes de Azevedo e doada por Francisco de Paula Goulart, reservou uma área determinada para a construção da futura igreja, a praça então adquiriu o nome do doador (REZENDE, 2006). Aos poucos com os esforços da comunidade, através de quermesses, doações e benfeitores, em meados de 1956 conseguiram construir uma pequena capela (Figura 01) atribuída a Paróquia São Sebastião (atualmente catedral), possuía um caráter de simplicidade e disposta a atender os moradores do bairro.

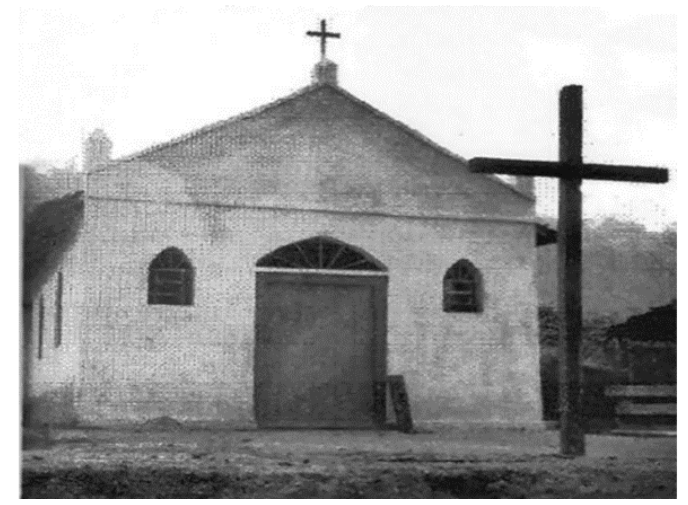

Figura 01. Primeira capela Nossa Senhora do Carmo

Fonte: Igreja Maristela (2016).

Segundo Rezende (2006) com o passar dos anos, a pequena capela expandiu seu número de fiéis carecendo assim, uma reforma e ampliação capaz de atender seu público. Esta ampliação foi concluída em 1967 e com ela, o Bispo Diocesano de Presidente Prudente da época, Dom José de Aquino Pereira, nomeou a comunidade Nossa Senhora do Carmo para o grau de paróquia. No mesmo dia, o novo templo, ao se desvincular da Paróquia São Sebastião, o Padre João Salgari foi designado ao cargo de primeiro pároco da Vila Maristela.

A partir desse período a paróquia cada vez mais evoluía em número de fiéis. Com a ajuda de colaboradores, a paróquia da Vila Maristela inicia em 1993 uma nova forma de evangelizar trazendo novos cursos, acampamentos e missões, tomando grandes proporções e atraindo a juventude da cidade (CAVALCANTE, 2010). Em 2004 a igreja passa por sua última reforma até os dias de hoje, demolindo completamente o antigo templo para construir o novo (Figura 02). 


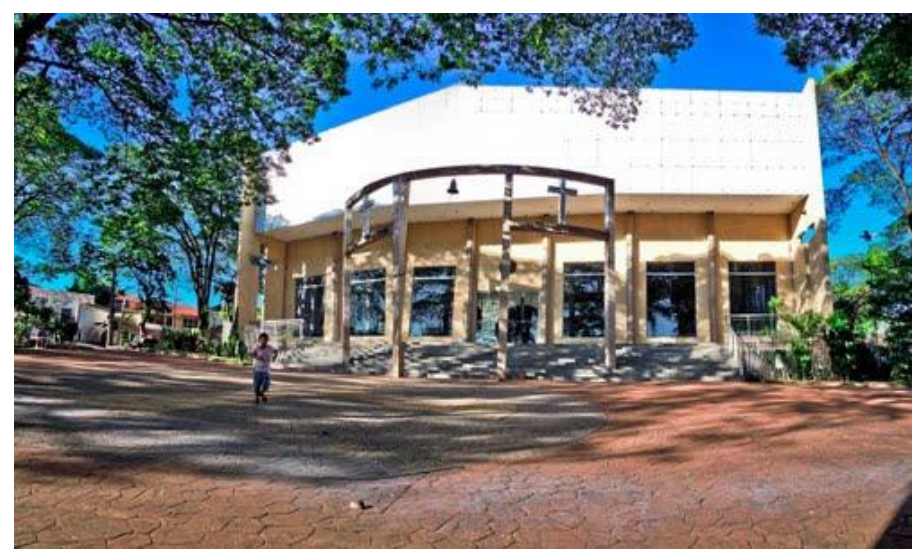

Figura 02. Nossa Senhora do Carmo em Presidente Prudente Fonte: Igreja Maristela (2016).

Atualmente, a paróquia conta com programas sociais que atuam na cidade como: casas de recuperação para dependentes químicos, ações sociais nas escolas, movimento de auxílio a portadores da síndrome da imunodeficiência adquirida (AIDS) e moradores de rua, trabalho de promulgação da paz e cidadania, entre outros (CAVALCANTE, 2010). Recebendo fiéis de todas as localidades e municípios próximos.

O trabalho com a juventude se destaca na paróquia Nossa Senhora do Carmo, por contar com elevado número de pessoas e atividades como pastorais jovens, dezoito acampamentos anuais, espiritualidades semanais e em média 700 crianças matriculadas na catequese (CAVALCANTE, 2010).

O salão paroquial, é destinado ao uso auxiliar do templo. Conta com a parte administrativa, recreativa e educativa da paróquia. O terreno está localizado entre o templo, situado sobre a praça Cel. Goulart no centro do quadrilátero do bairro e a linha férrea localizada no lado leste próxima ao Instituto Brasileiro do Café (IBC) atual centro de eventos e o condomínio residencial Príncipe de Andorra, interligando a rua Pe. João Salgari e a rua José Claro. $O$ acesso ao lote também é admissível pôr a Avenida Cel. José Soares Marcondes atravessando o bairro no sentido leste. (Figura 03)
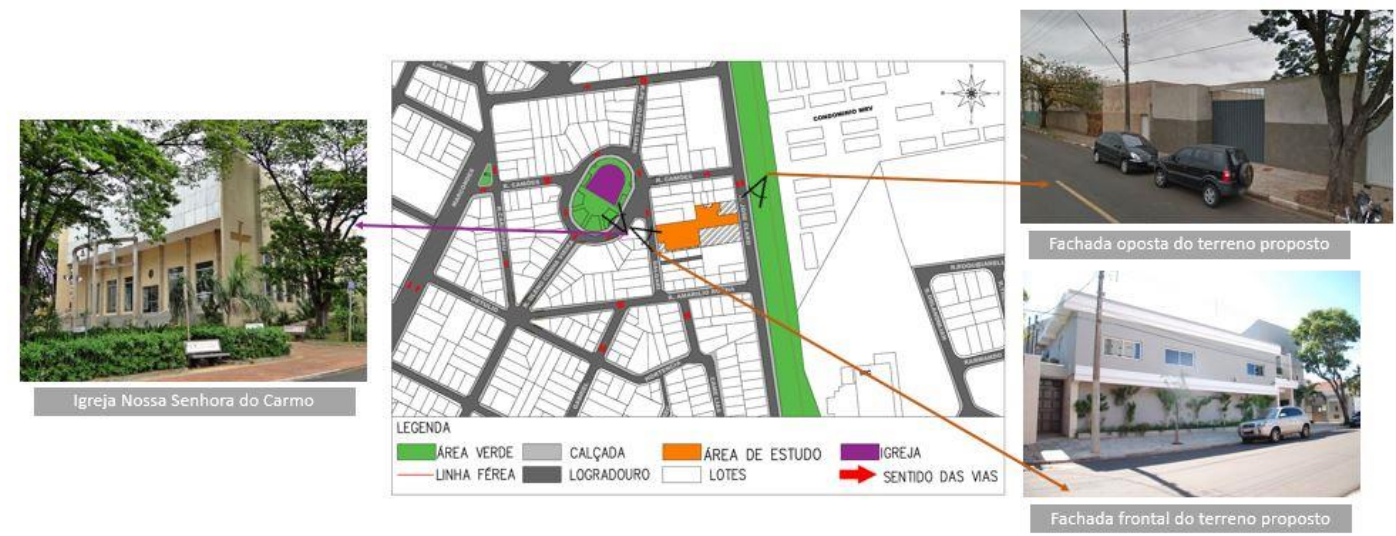

Figura 03. Localização e sentido das vias - sem escala

Fonte: Prefeitura Municipal de Presidente Prudente (2015). Modificado: autor (2016).

O pavimento térreo possui três acessos (Figura 04), sendo o principal destinado a área administrativa da paróquia, e a circulação vertical para o primeiro pavimento. O segundo acesso é mais restrito e destinasse a recepção para o auditório. $O$ terceiro acesso direciona-se para a única rampa do edifício para o primeiro pavimento. Por terem a construído sem planejamento, a 
inclinação inadequada da rampa não atende as Normas Brasileiras (NBR) da Associação Brasileira de Normas Técnicas (ABNT).

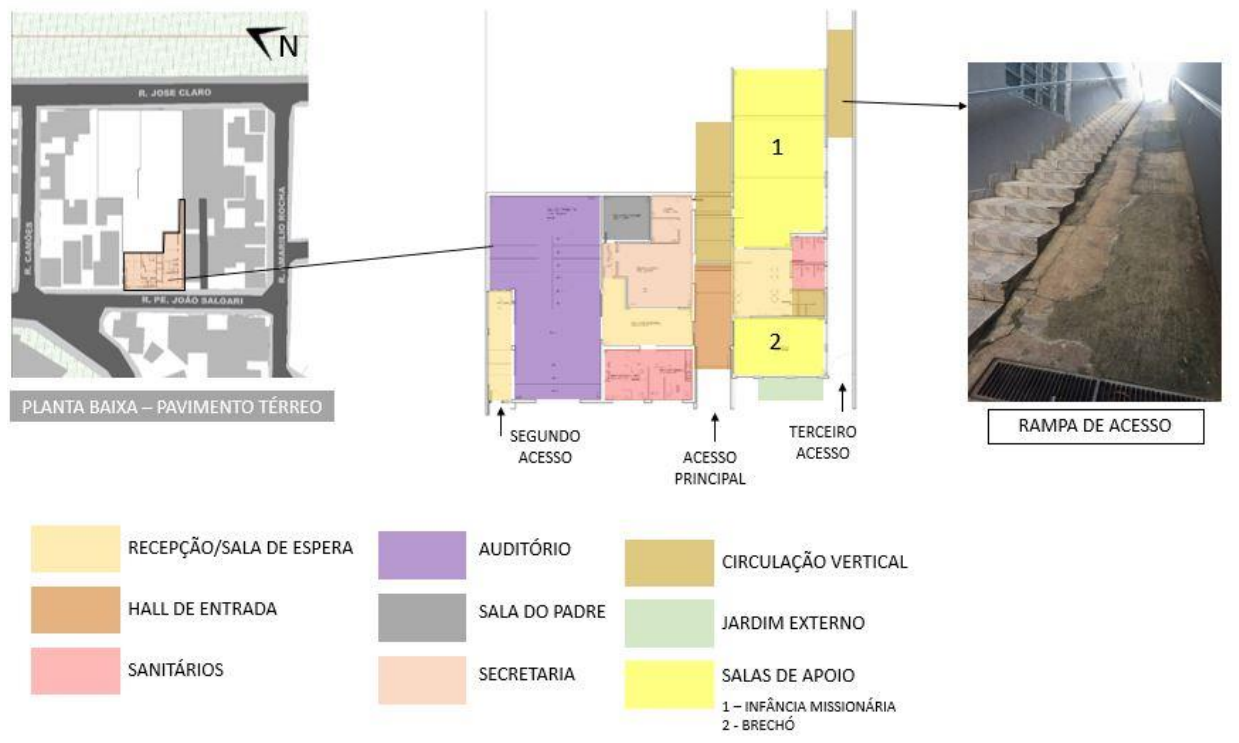

Figura 04. Planta Baixa - Pavimento térreo

Fonte: Autor (2016).

O segundo pavimento (Figura 05) se estende sobre toda a largura do quarteirão, e designado a atender a praticamente todas as atividades a cargo do edifício. $O$ salão principal voltado para um pequeno palco, se destaca por suas dimensões internas, e externamente seu teto côncavo é o responsável pela forma do volume. O salão principal possui limitada ventilação e iluminação natural, ocasionalmente em um ambiente desconfortável. Atrás do palco, um corredor direciona-se a uma pequena área de convívio pouco utilizada com vista para o templo, e duas salas de apoio, sendo uma dela destinada ao cinema.

A paróquia Nossa Senhora do Carmo é conhecida na região por ser a organizadora de uma festa gastronômica anual, denominada festa das nações, que mobiliza centenas de voluntários e consumidores, com isso, um estreito corredor ao fundo do salão principal reserva a cozinha da paróquia, onde são preparadas as comidas típicas, além de outros eventos. Ao fundo do corredor encontra-se um grande depósito a abriga os utensílios da festa das nações. Ainda no segundo pavimento, no lado sul situasse a capela do edifício, designada a tender as eventualidades de cada pastoral. 


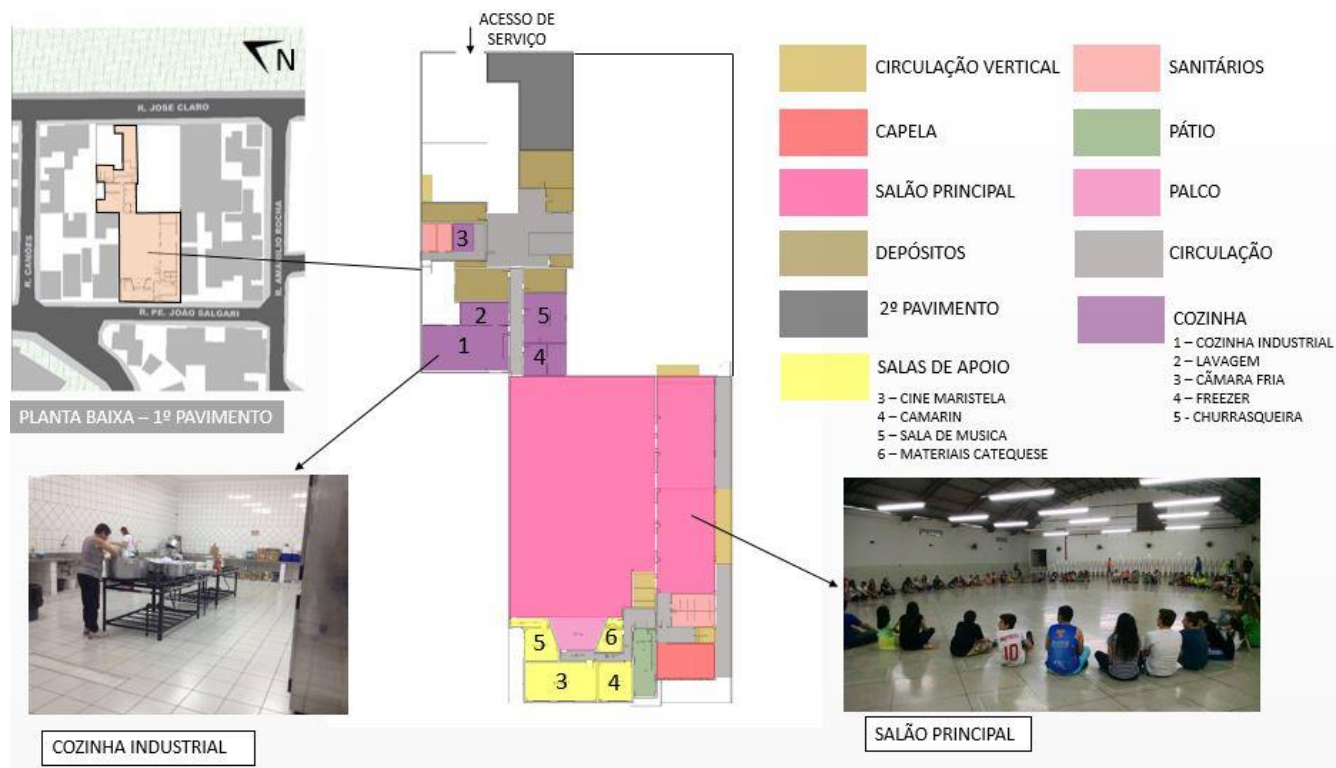

Figura 05. Planta Baixa - Primeiro Pavimento Fonte: Autor (2016).

O terceiro pavimento (Figura 06) possui cinco salas de aula, uma sala de coordenação e uma sala para materiais, dispostas ao longo de um estreito corredor com acesso a um terreno vazio pertencente a paróquia. As salas de aulas não suportam o crescente número de alunos. Além disso, o conforto de mobiliários para as diferentes faixas etárias é nulo e suas janelas não permitem a entrada de ventilação, devido a uma má instalação do aparelho de ar-condicionado.

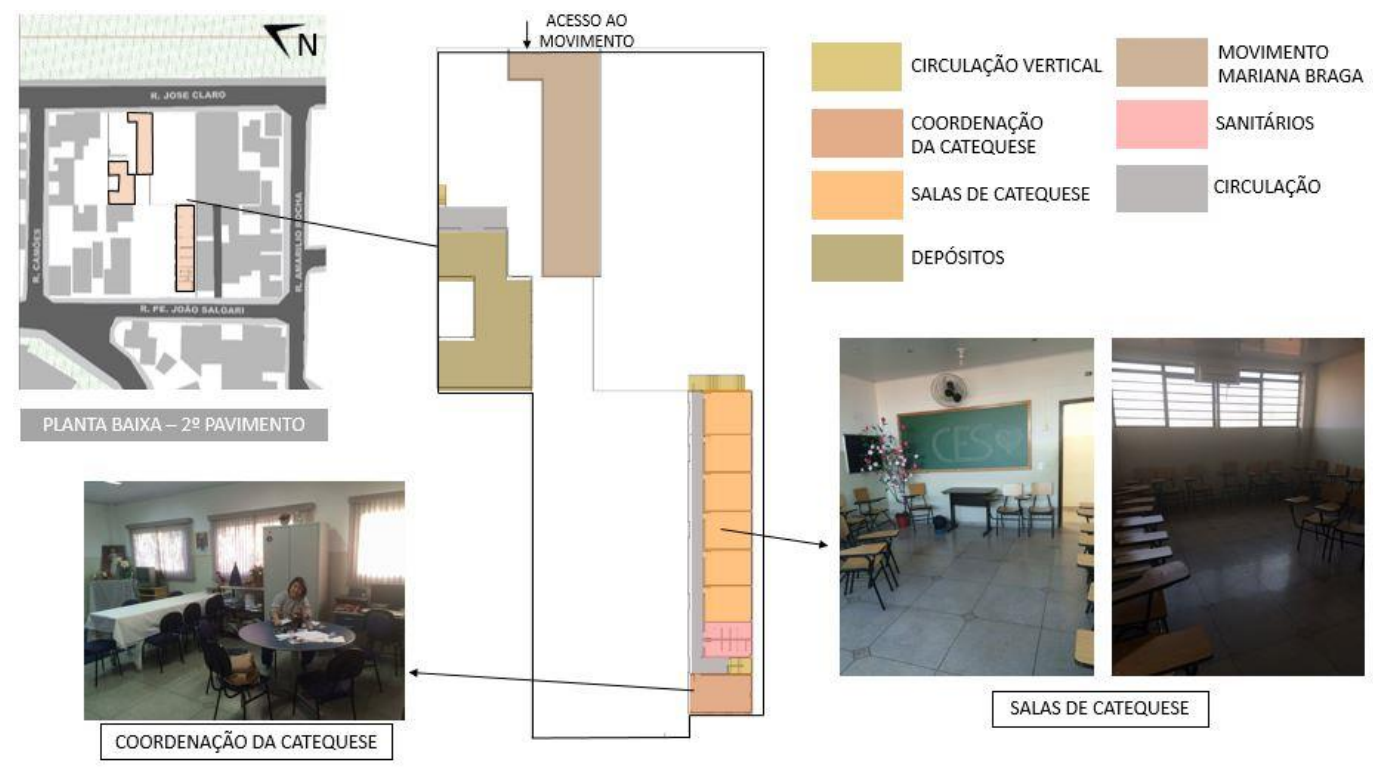

Figura 06. Planta Baixa - Primeiro Pavimento Fonte: Autor (2016).

\section{CONCLUSÃO}

A igreja ou lugar sagrado conforme determinada religião atua não apenas na vida espiritual do ser humano, mas também na vida social, este lugar se torna significante no cotidiano da vida da cidade. Com base nos estudos da paróquia Nossa Senhora do Carmo a população reconhece a importância do local por seu vínculo afetivo com os participantes do mesmo, porém apesar de propagar diversas atividades que resultam na socialização, a paróquia não possui espaços 
adequados capazes de enaltecer a relação do ser humano com o divino e a relação do mesmo com o outro. Acredita-se que o salão paroquial deva receber uma reestruturação arquitetônica, preservando a memória local de acordo com as necessidades da paróquia.

\section{REFERÊNCIAS}

CAVALCANTE, Mons. Expedito Pereira; SILVA, Ten. Cel. PM Carlos Amaral; SOUZA, Venicius Alves de. Poliantéia diocesana. Diocese de Presidente Prudente. 2010.

FABIEN, Jean. O Papel do Sagrado na Socialização Do Indivíduo. Jean Fabien. 2015. Disponível em <http://jeandefabien1426.blogspot.com.br/p/opapel-do-sagrado-na-socializacao-do.html>. Acesso em 15 de abril de 2016.

FRADE, Gabriel. Arquitetura Sagrada no Brasil. Sua evolução até as vésperas do concilio vaticano II. 1.ed. São Paulo: Loyola, 2007.

FRANCO, Mariana de Almeida Machado. Centro Cristão de Convivência. Anápolis, GO. 2011. Disponível em $<$ http://www.unucet.ueg.br/biblioteca/index.php?go=detalhesMonografia\&id=515\&a=4\&p=1\&curso=22>. Acesso em 29 de abril de 2016.

OLIVEIRA, Daniela Duarte de Freitas. A produção do espaço sagrado na arquitetura contemporânea - a interpretação da tradição católica a partir do séc. X. VOL I/VOLII. 2010. Dissertação (mestrado Arquitetura e Urbanismo) Universidade Federal de Minas Gerais. 2010.

VALBUZA, Thaynara Leal de Souza. Projeto Arquitetônico de templo religioso católico para o bairro aparecida do norte em coronel Fabriciano. Curso de Arquitetura e Urbanismo. Coronel Fabriciano. 2015. 